\title{
The role of zinc in the anti-tumour and anti-cachectic activity of D-myo-inositol 1,2,6-triphosphate
}

\author{
ST Russell', PMA Siren ${ }^{2}$, MJ Siren ${ }^{2,3}$ and MJ Tisdale ${ }^{*, 1}$ \\ 'Nutritional Biomedicine, School of Life and Health Sciences, Aston University, Birmingham B4 7ET, UK; ${ }^{2}$ Bioneris Ab, IAM, Adolf Fredriks Kyrkogata I3, \\ Stockholm III 37, Sweden; ${ }^{3}$ GK Memorial Research Library and Laboratory, Helsinki Töölön k 1900260, Finland
}

\begin{abstract}
BACKGROUND: D-myo-inositol-I,2,6-triphosphate ( $\alpha$-trinositol, AT) is a polyanionic molecule capable of chelating divalent metal ions with anti-tumour and anti-cachectic activity in a murine model.

METHODS: To investigate the role of zinc in this process, mice bearing cachexia-inducing MACI 6 tumour were treated with AT, with or without concomitant administration of $\mathrm{ZnSO}_{4}$.

RESULTS: At a dose of $40 \mathrm{mg} \mathrm{kg}^{-1}$, AT effectively attenuated both weight loss and growth of the MACl 6 tumour, and both effects were attenuated by co-administration of $\mathrm{Zn}^{2+}$. The concentration of zinc in gastrocnemius muscle increased with increasing weight loss, whereas administration of AT decreased the levels of zinc in plasma, skeletal muscle and tumour, which were restored back to control values after administration of $\mathrm{ZnSO}_{4}$.

CONCLUSION: These results suggest that zinc is important in both tumour growth and cachexia in this animal model. British Journal of Cancer (2010) 1 02, 833-836. doi:I0.1038/sj.bjc.6605562 www.bjcancer.com

Published online 9 February 2010

(c) 2010 Cancer Research UK
\end{abstract}

Keywords: cachexia; tumour growth; zinc; $\alpha$-trinositol

Trace metals such as zinc are essential components of many enzymes and transcription factors. Deficiency of zinc results in reduced food intake and growth, impaired synthesis of DNA and dysfunction of the immune system (MacDonald, 2000). Zinc has been shown to be involved in intracellular signalling events (Yamasaki et al, 2007), whereas an extracellular zinc-sensing receptor, not requiring zinc influx, has been shown to trigger the release of $\mathrm{Ca}^{2+}$ from intracellular stores (Hershfinkel et al, 2001). Although zinc is an essential trace element, high concentrations are toxic to cells, and zinc uptake, intracellular storage and efflux are carefully maintained (Kim et al, 2004).

There is evidence for aberrant zinc transport into tumour cells, and it has been suggested that zinc availability may be essential for tumour growth (Lee et al, 2003). Overexpression of the zinc transporter, ZIP4, compared with the surrounding normal tissue, is seen in $94 \%$ of clinical specimens of pancreatic adenocarcinoma, suggesting that it may contribute to the pathogenesis and progression of the disease ( $\mathrm{Li}$ et al, 2007). An increased expression of ZIP4 in pancreatic cancer cells increased intracellular zinc concentration, cell proliferation and tumour volume in nude mice. Zinc has also been shown to induce a dose-dependent increase in proliferation of the human prostate adenocarcinoma cell line, PC-3, and this was attenuated by the zinc chelator Ca EDTA (Dubi et al, 2008). Extracellular zinc also attenuated cell death. These results suggest that zinc chelation may be an effective measure to inhibit tumour growth.

*Correspondence: Professor MJ Tisdale; E-mail: m.j.tisdale@aston.ac.uk Received II September 2009; revised II January 2010; accepted II January 2010; published online 9 February 2010
There are also changes in zinc concentration in tumour and skeletal muscle of rats bearing a methylcholanthrene-induced fibrosarcoma during muscle wasting (Larsson et al, 1987). Thus, at 12 days after tumour transplantation, when cachexia is maximal, there is a significant decrease in serum zinc concentration, with a corresponding increase in both tumour and skeletal muscle. A progressive decrease in plasma zinc was also observed during growth of rat adenocarcinoma (Philcox et al, 1994). These results suggest that zinc may also have a role in the process of atrophy of skeletal muscle.

We have previously shown (Russell et al, 2009) that the polyanionic compound D-myo-inositol 1,2,6-triphosphate $(\alpha$-trinositol, AT) attenuated both tumour growth and muscle atrophy in mice bearing the cachexia-inducing MAC16 tumour. $\alpha$-Trinositol has been shown to chelate divalent metal ions such as $\mathrm{Ca}^{2+}$ and $\mathrm{Zn}^{2+}$, which bind to phosphates P1 and P6 of the inositol ring structure (Falemez and Speiss, 2001), but there have been no studies on whether this is important in the anti-cachectic and anti-tumour effect of AT. We hypothesised (PS and MJS) that zinc has an important role in the onset and progression of cancer cachexia. The current study investigates the role of zinc in the biological effects of AT in mice bearing the MAC16 tumour and its relationship to tumour growth and cachexia

\section{MATERIALS AND METHODS}

\section{Materials}

D-myo-inositol 1,2,6-triphosphate (AT) was supplied by JGK Memorial Research Library and Laboratory (Helsinki, Finland)/ Bioneris Ab (Stockholm, Sweden). 


\section{Animals}

The MAC16 tumour was passaged in pure strain male NMRI mice (average weight $25 \mathrm{~g}$ ), which were obtained from our own inbred colony, and were fed a rat and mouse breeding diet (Special Diet Services, Witham, UK) and water ad libitum. Tumour fragments were obtained from donor animals selected as those having the maximum weight loss, and were implanted s.c. into the flank by means of a trochar, as previously described (Bibby et al, 1987). Weight loss was evident from 10 days after tumour transplantation and animals were entered into the study when they had lost $\sim 5 \%$ of their starting body weight. Animals were randomised into groups of five to receive either solvent (PBS), AT $\left(40 \mathrm{mg} \mathrm{kg}^{-1}\right)$ or AT $\left(40 \mathrm{mg} \mathrm{kg}^{-1}\right.$ ) plus $8.05 \mu \mathrm{g} \mathrm{ZnSO}_{4}$ in $25 \mu \mathrm{l}$ PBS administered i.v. $1 \mathrm{~h}$ after AT. A fourth group received $\mathrm{ZnSO}_{4}$ alone. Both PBS and AT were administered s.c. three times a day. Tumour volume, body weight and food and water intake were monitored daily. Animals were killed by cardiac puncture under terminal anaesthesia when the body weight loss was at, or before, $20 \%$, as approved by the British Home Office. The ethical guidelines that were followed met the standards required by the UKCCR guidelines (Workman et al, 1998). Both tumour and gastrocnemius muscles were removed, snap frozen in liquid nitrogen and stored at $-80^{\circ} \mathrm{C}$ until measurement of zinc concentration.

\section{Measurement of zinc concentrations}

Tissues were weighed in crucibles, which were previously washed in 5\% Lipsol, and rinsed with deionised bio-filtered water, followed by trace analysis using nitric acid. The crucibles were placed in a furnace at room temperature, and the temperature was increased to $150^{\circ} \mathrm{C}$ for $1 \mathrm{~h}$, then $600^{\circ} \mathrm{C}$ for $2 \mathrm{~h}$, followed by $800^{\circ} \mathrm{C}$ overnight. A fine white ash, free from organic material, was obtained, and the crucibles were cooled and stored in desiccators. The crucibles were subsequently re-weighed to obtain the mass of ash, which was dissolved in $10 \mathrm{ml}$ of trace element analysis concentrated nitric acid and sonicated for $30 \mathrm{~min}$ to ensure stabilisation. The dissolved ash was then transferred to a $100 \mathrm{ml}$ volumetric flask, which was made up to volume with deionised bio-filtered water. The sample was then analysed for zinc using a PerkinElmer Analyst 100 atomic absorption spectrophotometer (PerkinElmer, Waltham, MA, USA), at a wavelength of $213.9 \mathrm{nM}$, slit $0.7 \mathrm{~mm}$, using air/acetylene gas and a lamp current of $10 \mathrm{~mA}$. Standards of known concentrations were used to construct calibration curves from which the concentration of zinc in the sample could be determined.

\section{Statistical analysis}

Results are presented as mean \pm s.e.m. Differences in means between groups were determined by one-way analysis of variance (ANOVA), followed by the Tukey-Kramer multiple comparison test. $P$-values $<0.05$ were considered significant.

\section{RESULTS}

The effect of AT on body weight of mice bearing the MAC16 tumour is shown in Figure 1A. A dose of $40 \mathrm{mg} \mathrm{kg}^{-1}$ of AT was chosen, as this has been shown to produce optimal inhibition of both weight loss and tumour volume (Russell et al, 2009). This study again showed that AT attenuated the loss of body weight produced by the MAC16 tumour, and this was completely reversed by administration of $\mathrm{Zn}^{2+} 1 \mathrm{~h}$ after AT. Administration of $\mathrm{Zn}^{2+}$ alone had no effect on weight loss compared with that of PBS controls. A similar result was obtained with regard to tumour volume (Figure 1B). Thus, AT also attenuated the tumour growth rate, and this was completely reversed by co-administration of $\mathrm{Zn}^{2+}$. However, $\mathrm{Zn}^{2+}$ alone inhibited tumour growth rate to the

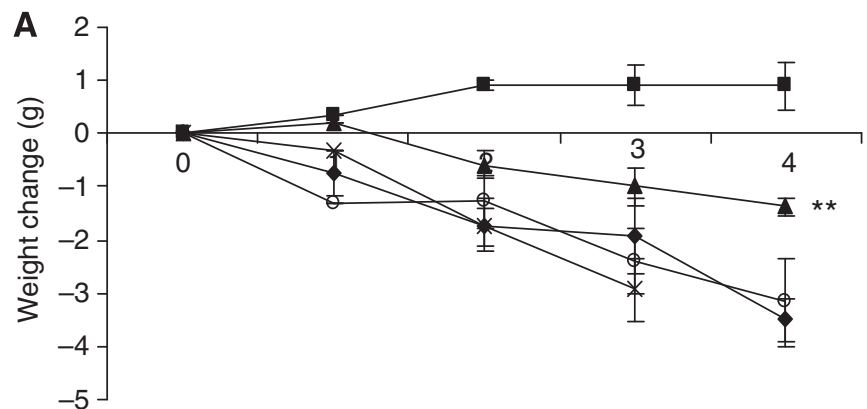

Time (days)

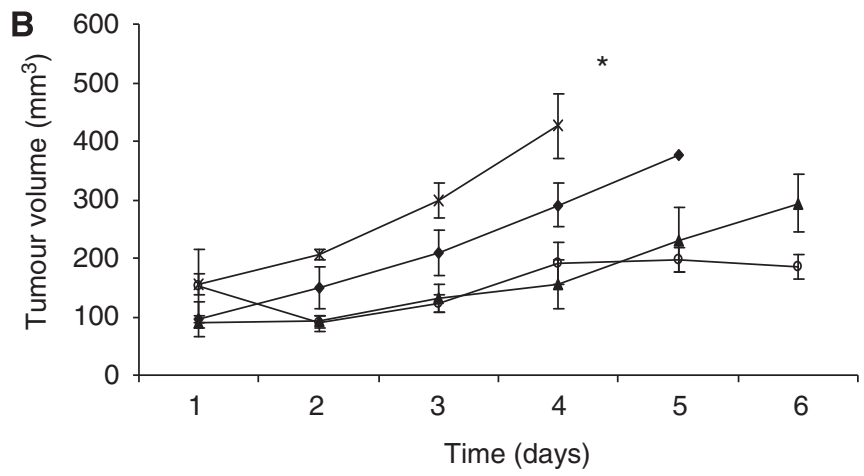

Figure I Weight change $(\mathbf{A})$ and tumour volume (B) in either nontumour-bearing mice $(\mathbf{\square})$ or in mice bearing the MACI 6 tumour treated with either PBS $(\bullet)$, AT $(\mathbf{\Delta})$, AT $+Z^{2} n^{+}(X)$ or $Z n^{2+}(O)$ at the doses and schedule as detailed in Materials and Methods. Differences from PBStreated animals are indicated as $* P<0.01$ or $* * P<0.001$.

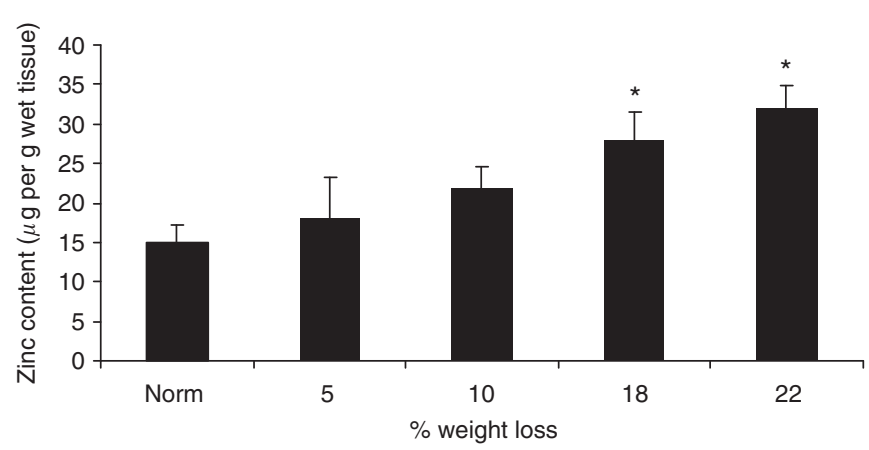

Figure 2 Zinc concentrations in gastrocnemius muscle of non-tumourbearing mice and mice bearing the MACl6 tumour and with different extents of weight loss. The results are expressed relative to non-tumourbearing animals after allowance for different muscle weights. Differences from non-tumour-bearing animals are shown as $* P<0.05$.

same extent as AT. These results show the importance of $\mathrm{Zn}^{2+}$ in the anti-cachectic and anti-tumour activity of AT.

As previously reported in weight-losing rats bearing a fibrosarcoma (Larsson et al, 1987), there was an increase in zinc concentration in the gastrocnemius muscle of mice bearing the MAC16 tumour, which became significant when weight loss was $<18 \%$ (Figure 2). There was no difference in the zinc concentration of plasma between tumour-bearing and non-tumour-bearing animals (Figure 3A). The reason for the accumulation of zinc in skeletal muscle is not known. However, treatment of mice bearing the MAC16 tumour with AT caused a significant reduction in zinc concentration in the plasma (Figure $3 \mathrm{~A}$ ), gastrocnemius muscle (Figure $3 \mathrm{~B}$ ) and tumour (Figure $3 \mathrm{C}$ ), when measured after 4 days 

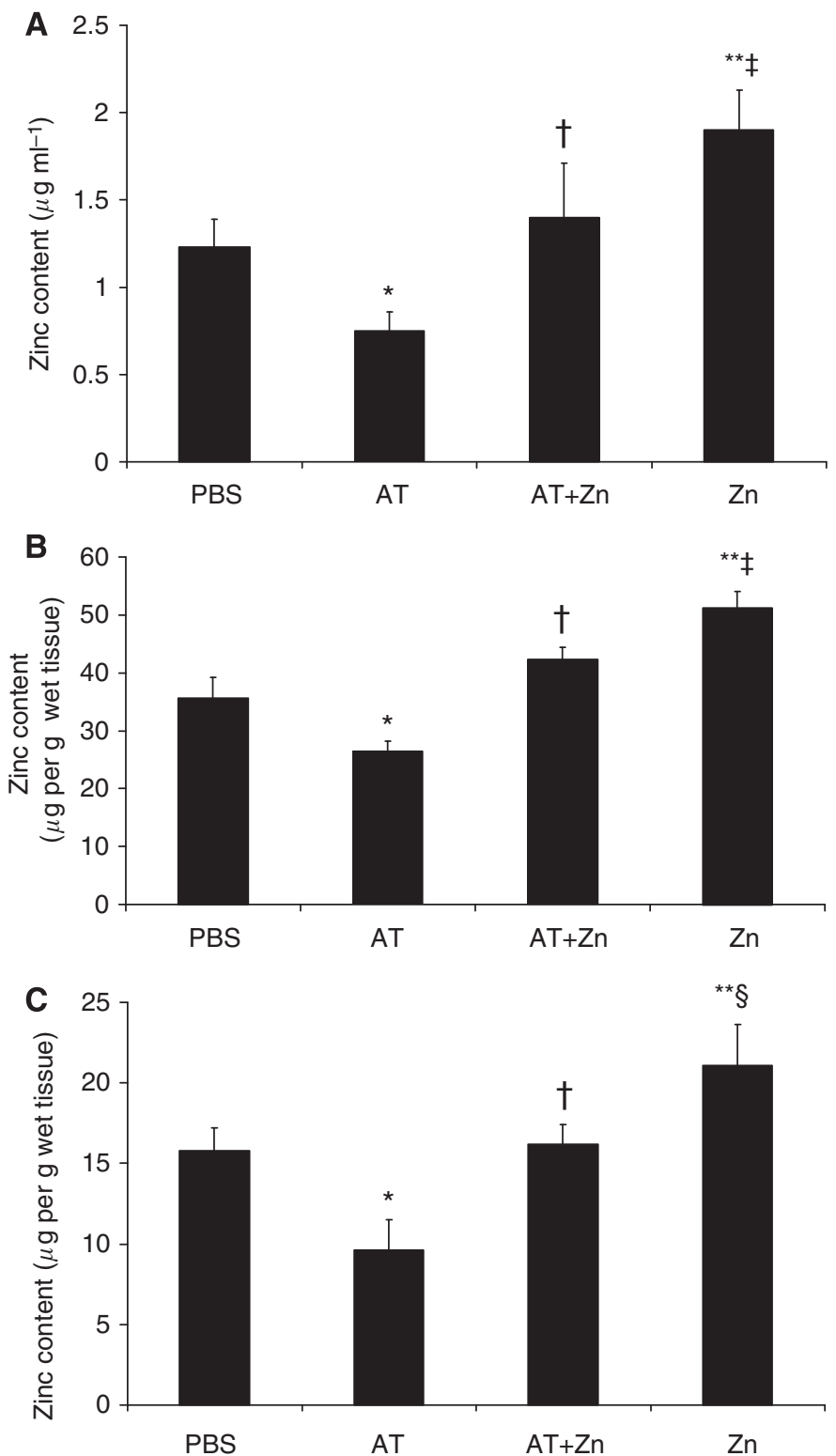

Figure 3 Concentration of zinc in plasma $(\mathbf{A})$, gastrocnemius muscle $(\mathbf{B})$ and tumour $(\mathbf{C})$ of mice bearing the MACl 6 tumour after 4 days of treatment with PBS, AT, AT plus $\mathrm{Zn}^{2+}$ or $\mathrm{Zn}^{2+}$ alone, as depicted in Figure I. Differences from PBS controls are shown as $* P<0.05$ or $* * P<0.01$, whereas differences from $A T$ are shown as ${ }^{\dagger} P<0.05$ and differences from $A T+Z n$ as ${ }^{\ddagger} P<0.05$ or ${ }^{\S} P<0.01$.

of treatment, as shown in Figure 1. Administration of $\mathrm{Zn}^{2+}$ to animals receiving AT increased the levels of $\mathrm{Zn}^{2+}$ in plasma, gastrocnemius muscle and tumour up to the levels found in PBS controls (Figure 3), consistent with the ability of $\mathrm{Zn}^{2+}$ to attenuate the action of AT on weight loss (Figure 1A) and tumour volume (Figure 1B). Administration of $\mathrm{Zn}^{2+}$ in the absence of AT caused a significant increase in the levels of $\mathrm{Zn}^{2+}$ in plasma, gastrocnemius muscle and tumour (Figure 3), consistent with an increase in weight loss and tumour volume (Figure 1). These results suggest that both tumour growth and weight loss may be limited by the availability of $\mathrm{Zn}^{2+}$.

\section{DISCUSSION}

The results of this study show the importance of $\mathrm{Zn}^{2+}$ in the process of both muscle wasting and tumour growth in mice bearing the MAC16 tumour. There have been few studies on the role of $\mathrm{Zn}^{2+}$ in skeletal muscle atrophy, although an increase in $\mathrm{Zn}^{2}+$ has been observed in the skeletal muscle of rats during the progress of cachexia (Larsson et al, 1987), as also observed in this study in mice bearing the MAC16 tumour. A similar result was obtained in mice transplanted with the Lewis Lung Carcinoma, which also produces cachexia (Frank et al, 1986). In this study, the zinc concentration in muscle was three times that of normal control, and there was also a re-distribution to the bone. One mechanism by which $\mathrm{Zn}^{2+}$ could participate in muscle atrophy is through activation of nuclear factor- $\kappa \mathrm{B}$ (NF- $\kappa \mathrm{B})$ through phosphorylation of p65/Rel A at multiple serine residues (Kim et al, 2007). Activation of NF- $\kappa \mathrm{B}$ in the muscle of mice has been shown to lead to atrophy through increased expression of proteasome subunits and the E3 ligase, MURF1 (Cai et al, 2004). It occurs through activation of caspases- 3 and -8 , and the subsequent autophosphorylation of the dsRNA-dependent protein kinase (PKR) (Suen et al, 2003). Autophosphorylation of PKR in skeletal muscle has been shown to inhibit protein synthesis owing to 
phosphorylation of eukaryotic initiation factor-2 (eIF2) on the $\alpha$-subunit, and increased protein degradation through the NF- $\kappa \mathrm{B}$ mediated induction of the ubiquitin-proteasome pathway (Eley and Tisdale, 2007). The activity of caspases-3 and -8, phosphorylation of PKR and eIF $2 \alpha$ and the activity and expression of the ubiquitin-proteasome pathway have been shown to be attenuated by AT in mice bearing the MAC16 tumour (Russell et al, 2009).

These results provide some evidence that the attenuation of loss of skeletal muscle by AT is separate from its anti-tumour activity, although both effects seem to be due to its ability to chelate $\mathrm{Zn}^{2+}$. Studies in vitro also support a separate role of AT in attenuating muscle atrophy. Thus, using murine myotubes as a model of skeletal muscle, AT has been shown to attenuate both the induction of protein degradation and depression of protein synthesis induced by proteolysis-inducing factor, angiotensin II, lipopolysaccharide and TNF- $\alpha$ (Russell et al, 2009 and unpublished results), and these effects could be reversed by addition of $\mathrm{Zn}^{2+}$. These studies also suggest that $\mathrm{Zn}^{2+}$ is required for the caspase-3/-8mediated activation of PKR. As AT is highly negatively charged, it is unlikely that it would readily penetrate into cells; hence, it is likely that the effects are mediated through the chelation of extracellular $\mathrm{Zn}^{2+}$.

In view of the potential mechanism by which AT attenuates tumour growth rate by chelation of $\mathrm{Zn}^{2+}$, and the role of zinc in the proliferation of pancreatic cancer ( $\mathrm{Li}$ et al, 2007), it was surprising that administration of $\mathrm{Zn}^{2+}$ alone attenuated tumour growth rate to the same extent as AT. However, it is known that although tumours need $\mathrm{Zn}^{2+}$ to grow and survive, excess $\mathrm{Zn}$ may induce apoptosis (Murakami and Hirano, 2008). Extracellular zinc has been shown to regulate growth and survival of prostate cancer cells through a putative zinc-sensing receptor (Dubi et al, 2008). Low concentrations of $\mathrm{Zn}^{2+}$ were shown to stimulate cell proliferation through activation of the mitogen-activated protein kinase and phosphatidylinositol-3-kinase pathways mediated by a Gq-coupled receptor. (Azriel-Tamir et al, 2004) However, high concentrations of $\mathrm{Zn}^{2+}$ led to desensitisation of the zinc receptor possibly through constitutive desensitisation, as for other G-protein-coupled receptors, and through inhibition of tumour growth. These results could explain the apparent anomaly that both chelators of $\mathrm{Zn}^{2+}$ and $\mathrm{Zn}^{2+}$ itself inhibit tumour growth.

These results suggest that AT is a novel agent with anti-cachectic and anti-tumour activity due to its ability to chelate $\mathrm{Zn}^{2+}$. Further studies are required on the role of $\mathrm{Zn}^{2+}$ in the signalling cascade leading to muscle atrophy, in order to elucidate the mode of action of this important metal in relation to cachexia.

\section{ACKNOWLEDGEMENTS}

This work was supported by a grant from Bioneris Ab. MJS was supported by the Paavo Nurmi Foundation (Helsinki, Finland). We thank Mr W Fleary for performing the in vivo study.

\section{REFERENCES}

Azriel-Tamir H, Sharir H, Schwartz B, Hershfinkel M (2004) Extracellular zinc triggers ERK-dependent activation of $\mathrm{Na}+\mathrm{H}+$ exchange in coloncytes mediated by the zinc-sensing receptor. J Biol Chem 279: 51804-51816

Bibby MC, Double JA, Ali SA, Fearon KCH, Brennan RA, Tisdale MJ (1987) Characterisation of a transplantable adenocarcinoma of the mouse producing cachexia in recipient animals. J Natl Cancer Inst 78: 539-546

Cai D, Frantz JD, Tawa Jr NE, Melendez PA, Oh B-C, Lidov HGW, Hasselgren P-O, Frontera WR, Lee J, Glass DJ, Shoelson SE (2004) IKK $\beta / \mathrm{NF}-\kappa \mathrm{B}$ activation causes severe muscle wasting in mice. Cell 119: $285-298$

Dubi N, Gheber L, Fishman D, Sekler I, Hershfinkel M (2008) Extracellular zinc and zinc-citrate, acting through a putative zinc-sensing receptor regulate growth and survival of prostate cancer cells. Carcinogenesis 29: $1692-1700$

Eley HL, Tisdale MJ (2007) Skeletal muscle atrophy, a link between depression of protein synthesis and increase in degradation. J Biol Chem 282: $7087-7097$

Falemez M, Speiss B (2001) Investigation of the ternary D-myo-inositol 1,2,6-tris (phosphate)-spermidine- $\mathrm{Zn}^{2+}$ system in solution. J Inorg Biochem 84: $107-111$

Frank AS, Schauble MK, Preiss IL (1986) Trace elements profiles in murine Lewis lung carcinoma by radioisotope-induced X-ray fluorescence. Am J Pathol 122: $421-432$

Hershfinkel M, Moran A, Grossman N, Sekler I (2001) A zinc-sensing receptor triggers the release of intracellular $\mathrm{Ca}^{2+}$ and regulates ion transport. Proc Natl Acad Sci USA 98: 11749-11754

Kim B-E, Wang F, Dufner-Beattie J, Andrews GK, Eide DJ, Petris MJ (2004) $\mathrm{Zn}^{2+}$-stimulated endocytosis of the mZIP4 zinc transporter regulates its location at the plasma membrane. J Biol Chem 279: $4523-4530$

Kim Y-M, Cao D, Reed W, Wu W, Jaspers I, Tal T, Bromberg PA, Samet JM (2007) $\mathrm{Zn}^{2+}$-induced NF- $\kappa$ B-dependent transcriptional activity involves site-specific p65/Rel A phosphorylation. Cell Sig 19: 538-546
Larsson S, Karlberg I, Selin E, Daneryd P, Petersen H-I (1987) Trace element changes in serum and skeletal muscle compared to tumour tissue in sarcoma-bearing rats. In Vivo 1: $131-140$

Lee R, Woo W, Wu B, Kummer A, Duminy H, Xu Z (2003) Zinc accumulation in $N$-methyl- $N$-nitrosouren-induced rat mammary tumours is accompanied by an altered expression of ZNT-1 and metallothionein. Exp Biol Med 228: 689-696

Li M, Zhang Y, Liu Z, Bharadwaj U, Wang H, Wang X, Zhang S, Liuzzi JP, Chang S-M, Cousins RJ, Fisher WE, Brunicardi FC, Logsdon CD, Chen C (2007) Aberrant expression of zinc transporter ZIP4 (SLC39A4) significantly contributes to human pancreatic cancer pathogenesis and progression. Proc Natl Acad Sci USA 104: 18636-18641

MacDonald RS (2000) The role of zinc in growth and cell proliferation. J Nutr 130: $1500 \mathrm{~S}-1508 \mathrm{~S}$

Murakami M, Hirano T (2008) Intracellular zinc homeostasis and zinc signalling. Cancer Sci 99: 1515-1522

Philcox JC, Tilley MH, Coyle P, Rofe AM (1994) Metallothionen and zinc homeostasis during tumor progression. Biol Trace Element Res 40: 295-308

Russell ST, Siren PMA, Siren MJ, Tisdale MJ (2009) Attenuation of skeletal muscle atrophy in cancer cachexia by D-myo-inositol 1,2,6-triphosphate. Cancer Chemother Pharmacol 64: 517-527

Suen KC, Yu MS, So KF, Chang RC, Hugon J (2003) Upstream signaling pathways leading to the activation of double-stranded RNA-dependent serine/threonine protein kinase in $\beta$-amyloid peptide neurotoxicity. J Biol Chem 278: 49819-49827

Workman P, Twentyman P, Balkwill F, Balmain A, Chaplin D, Double J, Embelton J, Newell D, Raymond R, Stables J, Stephens T, Wallace J (1998) United Kingdom Co-ordinating Committee on Cancer Research (UKCCR). Guidelines for the welfare of animals with experimental neoplasia (second edition). Br J Cancer 77: 1 - 10

Yamasaki S, Sakata-Sogawa K, Hasegawa A, Suzuki T, Kabu K, Sato E, Kurosaki T, Yamashita S, Tokunaga M, Nishida K, Hirano T (2007) Zinc is a novel intracellular second messenger. J Cell Biol 177: $637-645$ 